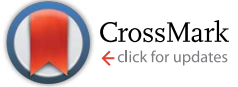

Cite this: RSC Adv., 2017, 7, 10700

Received 2nd November 2016 Accepted 1st February 2017

DOI: 10.1039/c6ra26183c

rsc.li/rsc-advances

\section{Polymerization of polyhedral oligomeric silsequioxane (POSS) with perfluoro-monomers and a kinetic study ${ }^{\dagger}$}

\author{
Jinmeng Hao, Yanfeng Wei, Bo Chen and Jianxin $\mathrm{Mu}^{*}$ \\ The polymerization of diphenol polyhedral oligomeric silsequioxane (2OH-DDSQ) with a series of \\ perfluoro-monomers including decafluorobiphenyl, decaflurobenzophenone and decafluorodiphenyl \\ sulfone was studied to obtain the optimized reaction for the preparation of POSS-containing fluorinated \\ poly(arylene ether)s. The kinetic behavior of the polymerizations was studied. All the reactants show high \\ reactivity even at a low temperature $\left(30{ }^{\circ} \mathrm{C}\right.$ in DMAc). Results show that the polymerization rate \\ increases with the increasing polarity of the perfluoro-monomers and the polymerization of $2 \mathrm{OH}-\mathrm{DDSQ}$ \\ with decafluorodiphenyl sulfone exhibits the highest rate constant at low temperatures of $30{ }^{\circ} \mathrm{C}, 40{ }^{\circ} \mathrm{C}$ \\ and $45{ }^{\circ} \mathrm{C}$. All of the reaction systems were slightly influenced by the reaction temperature due to the \\ low activation energy. The thermal properties of the polymers were also studied
}

\section{Introduction}

Fluoropolymers are very attractive for a broad range of advanced applications, because of their excellent optical and electronic properties, high thermal and chemical stabilities and low surface tension. ${ }^{1-3}$ However, fully fluorinated polymers such as polytetrafluoroethylene usually have high crystallinity which results in poor processability. Therefore, many partially fluorinated polymers with improved processability have been studied. ${ }^{4}$ Among them, poly(arylene ether)s containing perfluoro-monomers have shown relatively high fluorine content as well as easy processability which have been applied in low dielectric constant materials, ${ }^{5}$ optical waveguide devices ${ }^{6}$ and fluoride sensors. ${ }^{7}$

However, preparation of the poly(arylene ether)s from perfluoro-monomers which contain strong electro-withdrawing groups is difficult. ${ }^{8,9}$ The preparation of the traditional poly(arylene ether)s are usually following a nucleophilic aromatic substitution $\left(\mathrm{S}_{\mathrm{N}} \mathrm{A}_{\mathrm{r}}\right)$ mechanism by a diphenol and an aromatic difluoride via a one-step procedure. In the procedure, a Meisenheimer complex is formed when the phenoxide added to the aromatic difluoride and the formation of the Meisenheimer complex is the rate determining step. ${ }^{\mathbf{1 0}}$ Therefore, the electronwithdrawing groups of the aromatic difluoride which can stabilize the negative charge on the Meisenheimer complex will further activate the monomers and promote the overall reaction. For the perfluoro-monomers such as decafluorobiphenyl,

College of Chemistry, The Key Lab of High Performance Plastics, Ministry of Education, Jilin University, Changchun 130012, P. R. China. E-mail:jianxin_mu@jlu.edu.cn; Fax: +86-431-88498137; Tel: +86-431-88498137

$\dagger$ Electronic supplementary information (ESI) available. See DOI: $10.1039 / \mathrm{c} 6 \mathrm{ra} 26183 \mathrm{c}$ not only the 2 para-fluorines but also the 4 ortho-fluorines of the monomers are activated for the polymerization because of the strong electro-withdrawing effect of the additional fluorine atoms and the polymerization with monomers of multiple sites may result in branched and crosslinked structures. To obtain linear chain structure polymers which possess better solubility and flexibility in adjustability of the chemical structure, side reactions should be suppressed. Consequently, considering the difference in the reactivity of para and ortho-fluorines, a mild reaction condition such as low temperature should be used to suppress the side reaction for obtaining linear chain structure polymers with high molecular weights. ${ }^{11}$

In this paper, a diphenol POSS with good nucleophilicity is used to copolymerize perfluoro-monomers with different polarities via a two-step nucleophilic substitution procedure to prepare high molecular weight poly(arylene ether)s free of any crosslinked structure. ${ }^{12}$ POSS is a class of nanoscale molecule with an inorganic silicon and oxygen framework covered by organic substituents. ${ }^{13}$ Incorporating POSS into a polymer materials can dramatically improve its mechanical properties as well as thermal stability, ${ }^{14,15}$ nonflammability, ${ }^{16,17}$ oxidative resistance ${ }^{18}$ etc. A lot of POSS-containing materials have been synthesized for porous materials, ${ }^{19,20}$ magnetic materials, ${ }^{21,22}$ optical materials, ${ }^{23,24}$ superhydrophobic materials, ${ }^{25,26}$ catalyst supports and biomedical applications, such as scaffolds for drug delivery, imaging reagents, and combinatorial drug development. ${ }^{27,28}$ With POSS incorporated, poly(arylene ether)s are expected to possess desirable properties of organic and inorganic compounds. ${ }^{19-42}$

To suppress the side reaction, in this approach, the diphenol is first converted to phenoxide at a high temperature and then further reacted with perfluoro-monomers at a low temperature. The effects of reaction temperature and time were investigated 
and the kinetic equation and activation energy were evaluated to study the effect of the monomer polarities on the reaction and summarize the optimal condition of the polymerization. Theoretically, polymers containing both POSS and fluorine are usually with wide application potency. ${ }^{43-47}$ Meantime, many functional groups can be easily introduced into the polymers because of the mild reaction conditions. The design and preparation of the polymers are already on the way.

\section{Experimental section}

\section{Materials}

The diphenol POSS (2OH-DDSQ) was synthesized in our laboratory according to the literature ${ }^{\mathbf{1 2}}$ by hydrosilylation between 3,13-dihydro octaphenyl double-deckersilsesquioxane and eugenol. The perfluoro-monomers were abbreviated as DFPXs. Decafluorobiphenyl (DFP) and decaflurobenzophenone (DFPK) were purchased from Sigma-Aldrich and purified by recrystallization from 2-propanol prior to use. Decafluorodiphenyl sulfone (DFPS) was prepared according to reported methods. ${ }^{7}$ All other chemicals were obtained from commercial sources and used without further purification.

\section{Methods}

Thermogravimetric analysis (TGA) was performed to assess the thermal stability of membranes using a Perkin Elmer Pryis 1 TGA thermal analyzer under air atmosphere. Before performing the analysis, the samples were dried and kept inside the TGA furnace, which was isothermal at $100{ }^{\circ} \mathrm{C}$ for $20 \mathrm{~min}$. Then, the samples were reheated up to $800{ }^{\circ} \mathrm{C}$ at $10^{\circ} \mathrm{C} \mathrm{min}^{-1}$, and the temperatures that resulted in $5 \%$ and $10 \%$ weight losses were recorded for each sample. Differential Scanning Calorimeter (DSC) measurements were performed using a Mettler Toledo DSC $821^{\mathrm{e}}$ instrument at a heating rate of $20{ }^{\circ} \mathrm{C} \mathrm{min}^{-1}$ from $40{ }^{\circ} \mathrm{C}$ to $250{ }^{\circ} \mathrm{C}$ for DDSQDFPXs under nitrogen atmosphere. IR spectra (KBr pellets or films) were conduct on a Nicolet Impact 410 Fourier Transform Infrared Spectrometer (FTIR) at room temperature $\left(25^{\circ} \mathrm{C}\right)$. The samples were scanned within the range of $400-3200 \mathrm{~cm}^{-1} \cdot{ }^{1} \mathrm{H}$ NMR and ${ }^{19} \mathrm{~F}$ NMR spectra were obtained using Brüker Advance 400 spectrometer $(400 \mathrm{MHz})$. Gel permeation chromatograms were obtained using a Waters 410 instrument with dimethylformamide (DMF) as an eluant, at a flow rate of $1 \mathrm{~mL} \mathrm{~min}^{-1}$ using polystyrene as a standard. The crystallization behaviour of hybrid polymers were studied using a Rigaku D/max-2500 X-ray diffractometer with $\mathrm{CuK} \alpha$ radiation $(\lambda=0.154 \mathrm{~nm})$ as the $\mathrm{X}$-ray source.

\section{Polymer synthesis}

As shown in Scheme 1, DDSQ-DFP was synthesized via a twostep nucleophilic aromatic substitution procedure. To a 25 $\mathrm{mL}$ three-necked flask equipped with a mechanical stirrer, a nitrogen inlet, and a Dean-Stark trap with a condenser was added 2OH-DDSQ (1.4822 g, $1 \mathrm{mmol})$, DFP (0.3341 g, $1 \mathrm{mmol})$, anhydrous $\mathrm{K}_{2} \mathrm{CO}_{3}(0.1658 \mathrm{~g}, 1.2 \mathrm{mmol})$, DMAc $(10 \mathrm{~mL})$ and toluene $(4.5 \mathrm{~mL})$. The system was allowed to reflux for $3 \mathrm{~h}$, and then the toluene was removed. After removing toluene, the reaction mixture was cooled to $30{ }^{\circ} \mathrm{C}$ and then DFP was added.
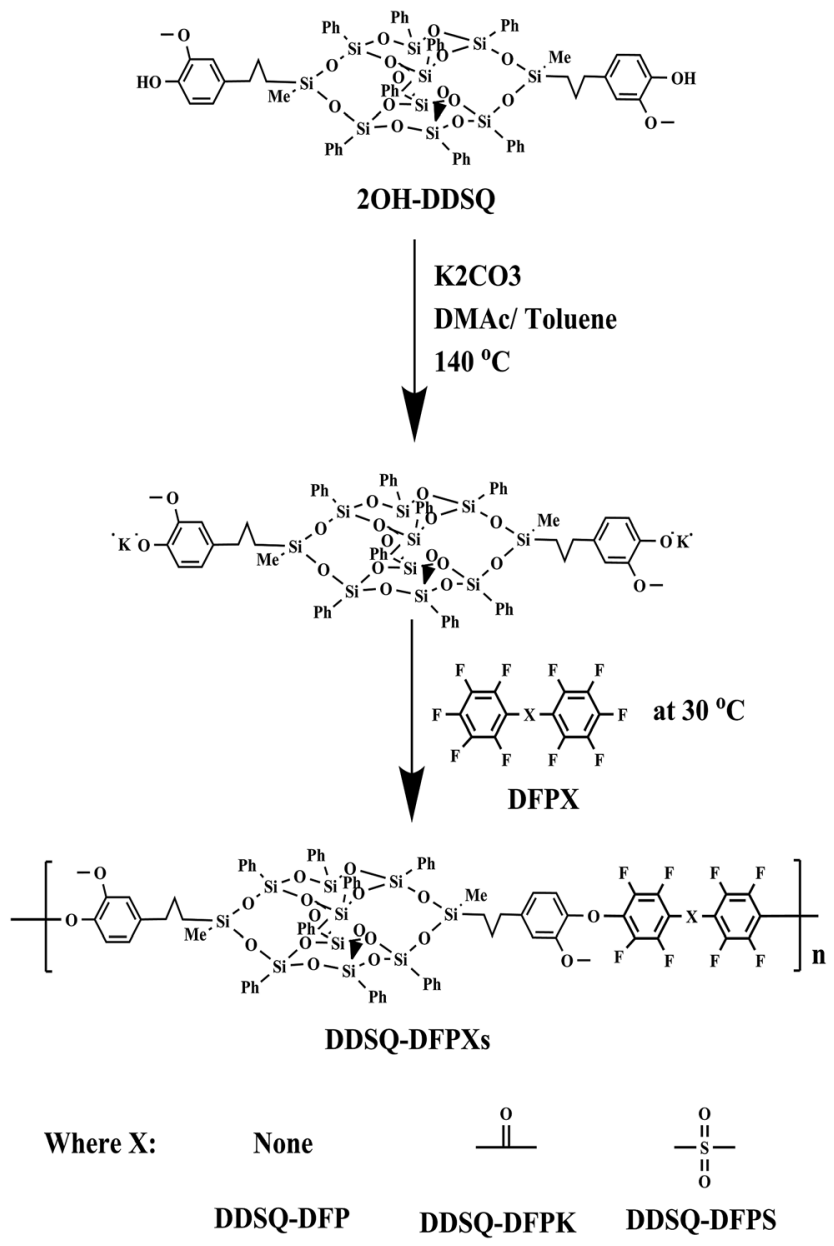

Scheme 1 Reaction route for the preparation of DDSQ-DFPXs.

The temperature was maintained for $8 \mathrm{~h}$ before the polymerization completed. During the procedure, a small number of reaction solution was removed at various reaction times for ${ }^{19} \mathrm{~F}$ NMR analysis. The final viscous solution was then poured into $50 \mathrm{~mL}$ of ethanol. The polymer was refluxed in deionized water and ethanol several times to remove the salts and solvents and was dried at $120{ }^{\circ} \mathrm{C}$ for $24 \mathrm{~h}$ (90\% yield). ${ }^{1} \mathrm{H}$ NMR $(400 \mathrm{MHz}$, DMSO-d $_{6}$ ), $\delta$ (ppm): $0.14(\mathrm{~m}), 0.63(\mathrm{~m}), 1.56(\mathrm{~m}), 2.42(\mathrm{~s}), 3.68(\mathrm{~s})$, 7.37 (m). ${ }^{19}$ F NMR (400 MHz, DMSO-d 6 ), $\delta(\mathrm{ppm}):-139.3(4 \mathrm{~F})$, -155.43 (4F). IR ( $\mathrm{KBr} \mathrm{cm}^{-1}$ ): 2927 (C-H stretching), 1643, 1507 (phenyl ring), 1304 (C-F stretching), 1071, 480 (Si-O stretching), 725 (Si-C stretching).

The other two polymers were prepared from the corresponding decafluorodiphenyl monomers and 2OH-DDSQ using the same procedure as described above with the reaction time and reaction temperature listed in Table 1 . The molecular weights of the polymers were measured with GPC and listed in Table 1.

DDSQ-DFPK (87\% yield). ${ }^{1} \mathrm{H}$ NMR (400 MHz, DMSO-d 6 ), $\delta(\mathrm{ppm}): 0.12(\mathrm{~m}), 0.64(\mathrm{~m}), 1.55(\mathrm{~m}), 2.36(\mathrm{~s}), 3.55(\mathrm{~s}), 7.376(\mathrm{~m})$. ${ }^{19}$ F NMR (400 MHz, DMSO-d 6 ), $\delta$ (ppm): -143.3 (4F), -155.4 (4F). IR (KBr cm ${ }^{-1}$ ): 2925 (C-H stretching), 1639, 1490 (phenyl ring), 1302 (C-F stretching), 1069, 475 (Si-O stretching), 720 (SiC stretching). 
Table 1 The preparation and characterization of DDSQ-DFPXs

\begin{tabular}{lllllll}
\hline DDSQ-DFPXs & Time $(\mathrm{h})$ & $M_{\mathrm{n}}(\mathrm{kDa})$ & PDI & Conversion values $(\%)$ & $T_{\mathrm{g}}\left({ }^{\circ} \mathrm{C}\right)$ & $T_{\mathrm{d} 5}\left({ }^{\circ} \mathrm{C}\right)$ \\
\hline DDSQ-DFP & 8 & 25.3 & 2.13 & 92.7 & 158 & 417 \\
DDSQ-DFPK & 6 & 21.6 & 2.25 & 91.5 & 144 & 408 \\
DDSQ-DFPS & 4.5 & 24.8 & 2.31 & 92.6 & 151 & 358 \\
\hline
\end{tabular}

DDSQ-DFPS (89\% yield). ${ }^{1} \mathrm{H}$ NMR (400 MHz, DMSO-d ${ }_{6}$ ), $\delta$ (ppm): $0.11(\mathrm{~m}), 0.65(\mathrm{~m}), 1.51(\mathrm{~m}), 2.35(\mathrm{~s}), 3.77(\mathrm{~s}), 7.37(\mathrm{~m}) .{ }^{19} \mathrm{~F}$ NMR (400 MHz, DMSO-d 6 ), $\delta$ (ppm): -138.7 (4F), -154.5 (4F). IR ( $\mathrm{KBr} \mathrm{cm}^{-1}$ ): 2920 (C-H stretching), 1635, 1483 (phenyl ring), 1298 (C-F stretching), 1069, 478 (Si-O stretching), 720 (Si-C stretching).

\section{Results and discussion}

\section{Polymerization of 2OH-DDSQ with DFPXs}

The polymerization of DFPXs and 2OH-DDSQ was carried out in a two-step nucleophilic aromatic substitution procedure. In this approach, the 2OH-DDSQ was first converted to phenoxide and then further reacted with DFPXs at a low temperature of $30{ }^{\circ} \mathrm{C}$. The reactions are displayed in Scheme 1 and analyzed by ${ }^{19} \mathrm{~F}$ NMR in Fig. 1. It can be seen that the produced polymers have clean ${ }^{19} \mathrm{~F}$ NMR spectra and the two major peaks are assigned to the fluorine atoms on the main chain as indicated in the Fig. 1. The only three tiny peaks correspond to the fluorine atoms on the end group. This means that the side reactions in the ortho, and meta fluorine atoms are strongly suppressed under the mild condition. Actually the reaction at a temperature of $60{ }^{\circ} \mathrm{C}$ for DFP and 2OH-DDSQ could yield crosslinked gels in only 15 minutes and the temperatures for the other reactions to get crosslinked gels are even lower.

To investigate the reaction process of the DDSQ-DFPXs, as an example, Fig. 2 shows the ${ }^{19}$ F NMR spectra of DDSQ-DFP at different reaction times. As shown in Fig. 2, as the reaction time increased, two new peaks appeared (-139.3 (a), -155.4 (b) ppm) and increased in intensity which were attributed to the ortho

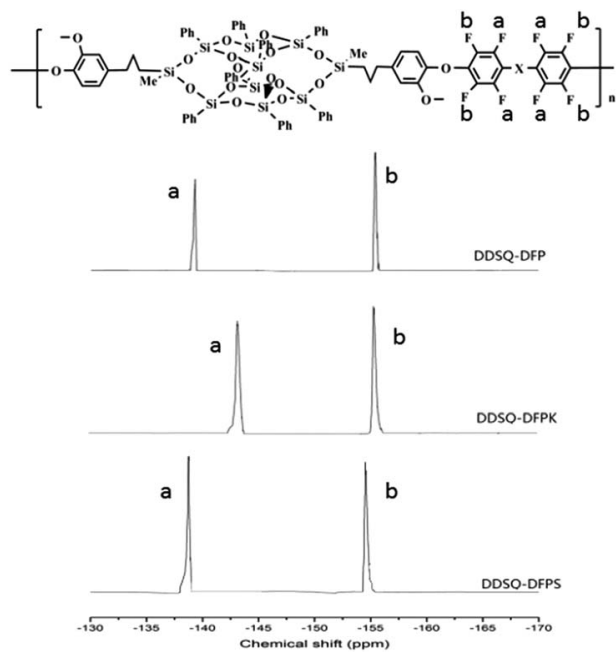

Fig. $1{ }^{19}$ F NMR spectra of the DDSQ-DFPXs in DMSO- $d_{6}$.

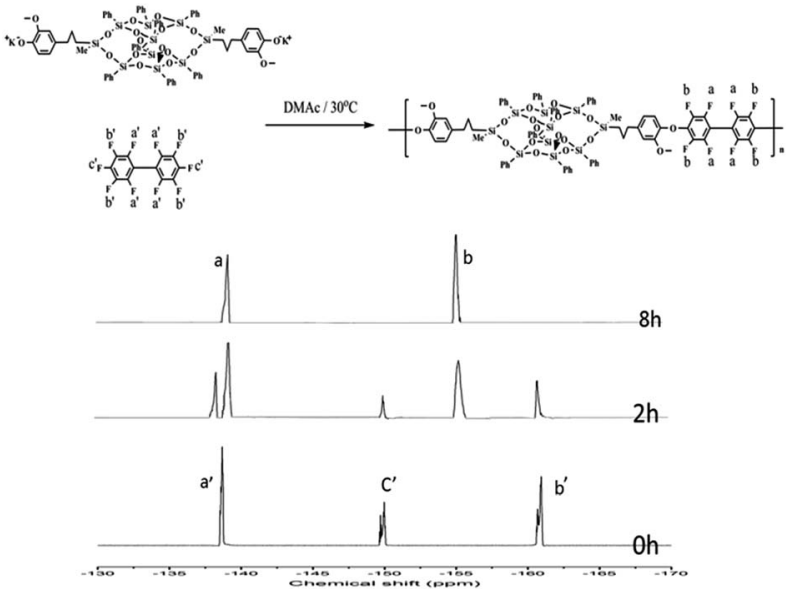

Fig. $2{ }^{19}$ F NMR spectra of DDSQ-DFP at different reaction times.

and meta fluorine atoms on the main chain of the polymer. Meanwhile, three other peaks decreased (-138.5 (ppm), -150.1 (ppm), -160.9 (ppm)) in density, which were attributed to the ortho, para and meta fluorine atoms of the DFP end units in the polymer. From the Fig. 2 it can be seen that at the reaction time of $8 \mathrm{~h}$, the peaks of ortho, and meta-fluorine atoms can barely be seen. At the end this period about $92.7 \%$ of DFP was converted to the di-substituted compound. Moreover, when the reaction time gets longer, the solution becomes highly viscous and a gellike substance formed. However, the isolated polymer from the solution was found to be soluble in DMAc and there is no extra peaks in the ${ }^{19} \mathrm{~F}$ NMR spectra indicating no branched or crosslinked structure in the gel-like substance. The solubility of the DDSQ-DFP becomes poor and precipitate from the solution when the molecule weight gets high. From the Table 1, it can be seen that the molecular weight of DDSQ-DFPXs are relatively high compared with the other POSS-containing polymers though the numbers of the repeating units in the polymers are all less than 15 .

The polymers were also identified by FTIR and ${ }^{1} \mathrm{H}$ NMR spectroscopy (Fig. 3). The FTIR spectra of the DDSQ-DFPXs show characteristic absorption bands around $1650 \mathrm{~cm}^{-1}$ and $1304 \mathrm{~cm}^{-1}$, corresponding to aryl carbonyl groups and carbonfluorine bonds. Fig. 3 shows the ${ }^{1} \mathrm{H}$ NMR of DDSQ-DFPXs. Signals of proton at $0.13,0.65-2.4$ and $3.56 \mathrm{ppm}$ are assigned to the protons of methyl, methylene, and methoxy. The peaks at 6.2-8.5 are assigned to the protons of aromatic rings.

\section{Kinetic study of the reaction}

As a two-step nucleophilic aromatic substitution procedure polymerization, the diphenol was first converted to phenoxide 

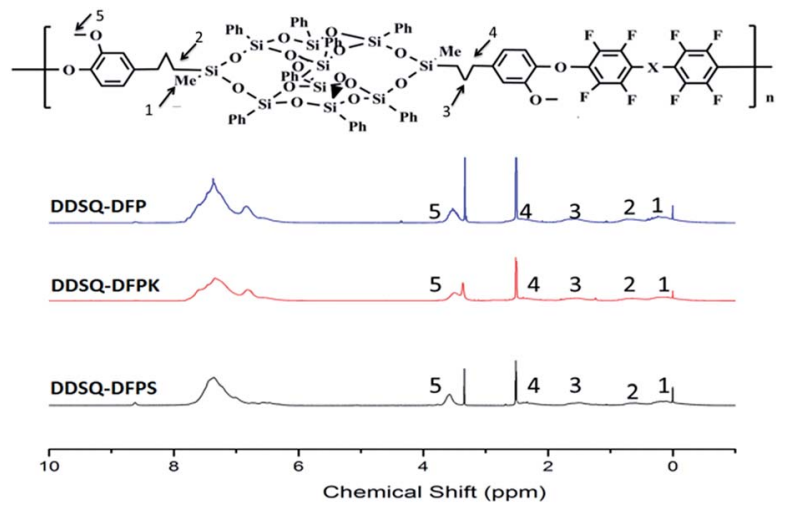

Fig. $3{ }^{1} \mathrm{H}$ NMR spectra of DDSQ-DFPXs in DMSO- $\mathrm{d}_{6}$.

and then further reacted with DFPXs at a low temperature. The first procedure is not directly participating in the polymerization. And the second procedure can be explained by the Scheme 2 , following the nucleophilic aromatic substitution $\left(S_{N} A_{r}\right)$ mechanism. Typically, the formation of Meisenheimer complex is the rate-determining step.

The rate expression $R_{\mathrm{p}}$ for polymerization in Scheme 2 can be described as the following eqn (1):

$$
R_{\mathrm{p}}=-\frac{\mathrm{d} c}{\mathrm{~d} t}=k_{1} c_{1} c_{2}
$$

$c_{1}$ : molar concentration of DFPXs; $c_{2}$ : molar concentration of the phenoxide; $k_{1}$ : the reaction rate constant of polymerization and the rate constant for the formation of the Meisenheimer. It was assumed that the molar concentrations of DFPXs and the phenoxide were equal and described as $c$. The above equation can be simplified as follow:

$$
R_{\mathrm{p}}=-\frac{\mathrm{d} c}{\mathrm{~d} t}=k_{1} c^{2}
$$

indicating a second-order reaction.

After integration, the equation was shown as

$$
\frac{1}{c}-\frac{1}{c_{0}}=k_{1} t
$$

with $c_{0}$, the initial concentration of the DFPXs and phenoxide and $c$, the concentration of the DFPXs and phenoxide at time $t$. There is an equation between $c$ and $c_{0}$ following $c=c_{0}(1-p)$ and $p$ is the conversion at reaction time $t$. So the eqn (2) can be further described as the following eqn (4):

$$
\frac{1}{1-p}=1+c_{0} t
$$

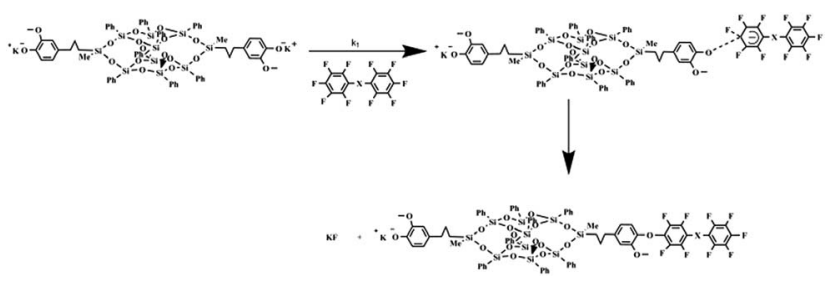

Scheme 2 Reaction mechanism for the polymerization.
By comparing the integral intensity of the fluorine atoms in the ${ }^{19} \mathrm{~F}$ NMR spectra, the conversion at different reaction times can be calculated following $p=\left(F_{0}-F_{t}\right) / F_{0}$ with $F_{0}$ the initial concentration of para-fluorine and $F_{t}$ the concentration of parafluorine at time $t$. The relation of the $1 /(1-p)$ with the reaction time $t$ in the related three reaction systems are presented in the Fig. 5. It can be found that the experimental data can fit the equation when the conversion is less than $83 \%$ reflecting the $\mathrm{S}_{\mathrm{N}} \mathrm{A}_{\mathrm{r}}$ mechanism of the reaction. According to the eqn (1) and Fig. 4 , the reaction rate constant at $30{ }^{\circ} \mathrm{C}$ can be calculated due to the slope of the curve. The values of the reaction rate constants are shown to be $0.271,0.307,0.483 \mathrm{~L} \mathrm{~mol}^{-1} \mathrm{~min}^{-1}$ which increase with the increasing of polarity of the DFPXs.

\section{Activation energy of the polymerization}

Since the present reaction was conducted at a temperature of $30{ }^{\circ} \mathrm{C}$, for the calculation of the activation energy and investigation of the temperature effect on the reaction system, the reaction was also investigated at various temperatures. Kinetic parameters of the reaction systems are listed in Table 2 . As an example, Fig. 6 shows the variation of $1 /(1-p)$ with the reaction

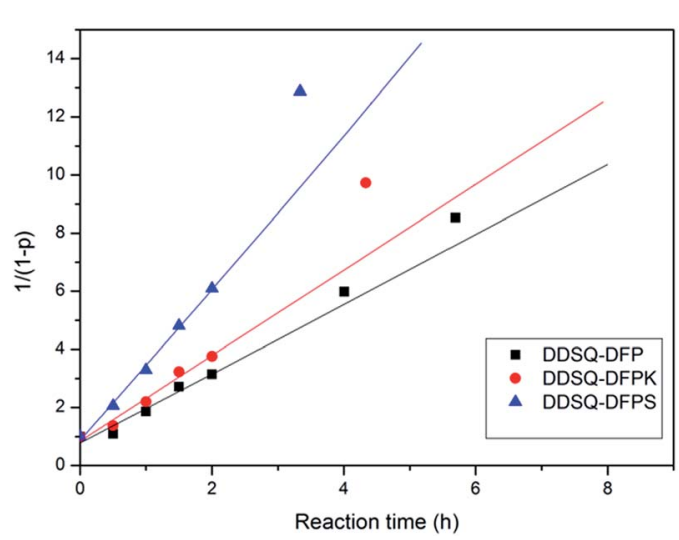

Fig. 4 Dependence of $1 /(1-p)$ on the reaction time for the DDSQDFPXs produced in DMAC at $30{ }^{\circ} \mathrm{C}$.

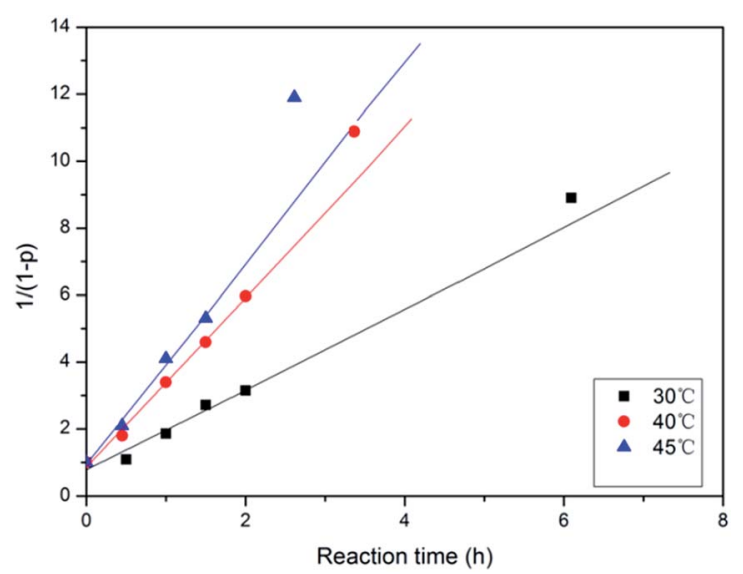

Fig. 5 Dependence of $1 /(1-p)$ on the reaction time for the DDSQDFP produced in DMAc at $30{ }^{\circ} \mathrm{C}, 40^{\circ} \mathrm{C}$ and $45^{\circ} \mathrm{C}$. 
Table 2 Kinetic parameters of the reaction systems; rate constant $k$ and activation energy $E_{a}$

\begin{tabular}{llll}
\hline DDSQ-PAEKs & $T\left({ }^{\circ} \mathrm{C}\right)$ & $k\left(\mathrm{~L} \mathrm{~mol}^{-1} \mathrm{~min}^{-1}\right)$ & $E_{\mathrm{a}}\left(\mathrm{kJ} \mathrm{mol}^{-1}\right)$ \\
\hline DDSQ-DFP & 30 & 0.271 & 32.14 \\
& 40 & 0.414 & \\
DDSQ-DFPK & 45 & 0.503 & 27.52 \\
& 30 & 0.307 & \\
DDSQ-DFPS & 40 & 0.431 & 25.11 \\
& 45 & 0.510 & \\
& 40 & 0.483 & \\
& 45 & 0.643 &
\end{tabular}

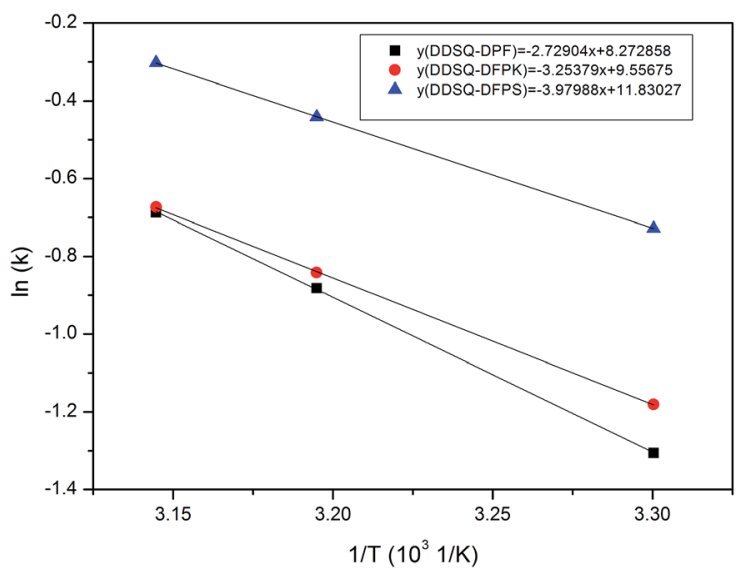

Fig. 6 Dependence of $\ln k$ on the reaction temperature for the DDSQ-DFPXs produced in DMAc at $30^{\circ} \mathrm{C}, 40^{\circ} \mathrm{C}$ and $45^{\circ} \mathrm{C}$.

time for the DDSQ-DFP produced in DMAc at $30{ }^{\circ} \mathrm{C}, 40{ }^{\circ} \mathrm{C}$ and $45{ }^{\circ} \mathrm{C}$. It can be seen that increasing the temperature from $30^{\circ} \mathrm{C}$ to $45^{\circ} \mathrm{C}$ results in an about 1.5 -fold increase in the rate constant reflecting a low activation energy. The activation energy $E_{\mathrm{a}}$ values are calculated following the Arrhenius equation:

$$
k=A \mathrm{e}^{-\frac{E_{\mathrm{a}}}{R T}}
$$

$T$ : temperature in $\mathrm{K} ; R$ : universal gas constant with the value of $8.314 \mathrm{~J} \mathrm{~mol}^{-1} \mathrm{~K}^{-1}$; $A$ : pre-exponential factor. The equation can be transformed into the following eqn (6):

$$
\ln \frac{k_{2}}{k_{1}}=\frac{E_{\mathrm{a}}}{R}\left(\frac{1}{T_{1}}-\frac{1}{T_{2}}\right)
$$

$k_{1}$ : rate constant at $T_{1} ; k_{2}$ : rate constant at $T_{2}$.

The variation of $\ln k$ with $1 / T$ for the DDSQ-DFPXs are shown in Fig. 6 and according to the eqn (6) the activation energy values can be calculated from the slopes indicated in the figure. The corresponding $R$-squares for DDSQ-DFP, DDSQ-DFPK and DDSQDFPS are $0.99235,0.98753,0.9889$ which indicate the high correlation between $\ln k$ and the reaction temperature. The reactions between 2OH-DDSQ and perfluro-monomers are all shown to have low activation energy with the $E_{\mathrm{a}}$ below $35 \mathrm{~kJ} \mathrm{~mol}^{-1}$.

As a nucleophilic aromatic substitution $\left(S_{N} A_{r}\right)$ reaction, the nucleophilicity of the diphenol and the stability of the
Meisenheimer complex are important for low activation barriers leading to relatively low activation energy. The phenoxide of the $2 \mathrm{OH}-\mathrm{POSS}$ has a high nucleophilicity because of the electron-donating effect of the ortho-substituted methoxy and meantime, the electron-withdrawing groups of the perfluoromonomer further stabilize the Meisenheimer complex. As explained the above two main reasons lead to a relatively low activation energy. It can be seen that the activation energy $E_{\mathrm{a}}$ decreases with the increasing polarity of the DFPXs. This is because the stronger electro-withdrawing effect gets a stabler Meisenheimer complex.

\section{Thermal properties of DDSQ-DFPXs}

The thermal properties of the DDSQ-DFPXs were evaluated by DSC and TGA, and the data are listed in Table 1 and the curves are shown in Fig. 7 and 8. No melting endotherms are observed in DSC traces for the DDSQ-DFPXs (Fig. 7), which suggests their amorphous nature. Among the polymers, DDSQ-DFP shows the highest $T_{\mathrm{g}}$ value $158{ }^{\circ} \mathrm{C}$ because of the effect of the rigid biphenylene polymer backbone which hinders the movement of the chain segment. With the increasing of polarity of the DFPXs, DDSQ-DFPS exhibits a higher $T_{\mathrm{g}}$ than DDSQ-DFPK, reflecting a higher intermolecular force in the polymer. Meanwhile, the polymers don't show very high $T_{\mathrm{g}} \mathrm{s}$. Though the rigid molecular

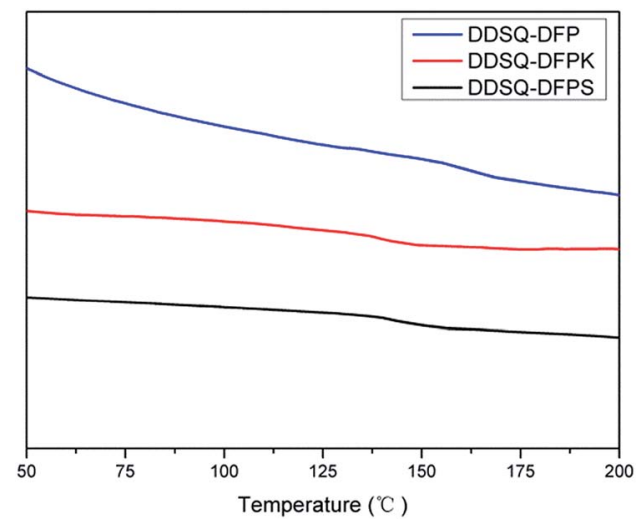

Fig. 7 DSC curves of the DDSQ-DFPXs.

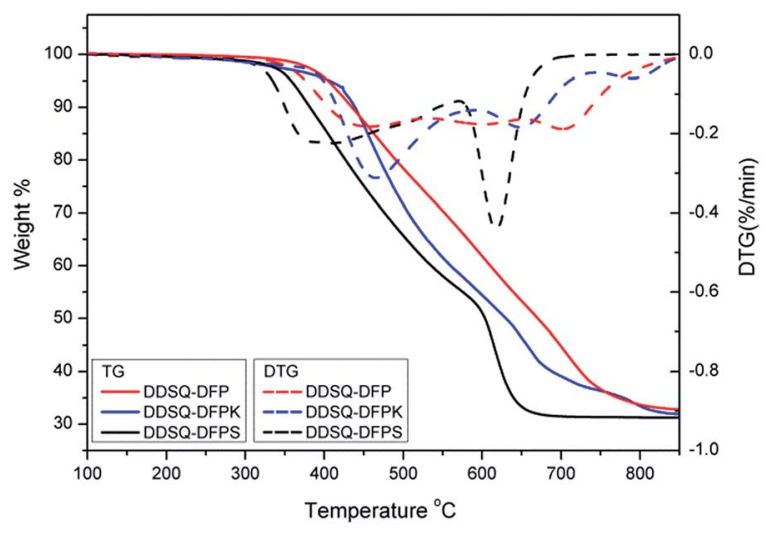

Fig. 8 TGA curves and the derivative curves of the DDSQ-DFPXs. 
structure of POSS can lead a higher $T_{\mathrm{g}}$, both the greatly increased free volume of DDSQ-DFPXs and the flexible aliphatic chains possessed by $2 \mathrm{OH}-\mathrm{DDSQ}$ results in the easier movement of the chain segment.

Seen from the TGA data Table 1 and Fig. 8, the temperatures at $5 \%$ weight loss $\left(T_{\mathrm{d} 5}\right)$ are in the range of $358-417^{\circ} \mathrm{C}$ in air for the DDSQ-DFPXs, indicating a fairly high thermal stability of the polymers. It can be seen from the derivative curves in Fig. 8 that all the polymers display two steps in degradation progress. The first step from $335{ }^{\circ} \mathrm{C}$ to $570{ }^{\circ} \mathrm{C}$ originated from the degradation of active alkyl chain and the second step from $570{ }^{\circ} \mathrm{C}$ to $760{ }^{\circ} \mathrm{C}$ originated from the degradation of frameworks, such as the aromatic ring and POSS cage. The DDSQDFPXs display high residuals of degradations which are all above $30 \%$. The high yields of degradation residues are ascribed to the ceramic formation from POSS moiety during the thermal decomposition.

\section{Conclusion}

The polymerization of 2OH-DDSQ with DFPXs can be conducted at a low temperature of $30^{\circ} \mathrm{C}$ in DMAc via a two-step procedure obtaining polymers with high molecular weights and well-defined linear chain structures. The reactants exhibit high reactivity allowing the polymerization to complete in a few hours. The reaction rate increases with the increasing of polarity of the DFPXs and it is found that the reaction rate is not greatly affected with the increasing temperature. The activation energy of the polymerization is shown to be very low and the values decreases with the polarity of the DFPXs. With the wellcontrolled reaction time, all the produced polymers have great fundamental properties for future application such as solubility and thermal properties. The polymers with POSS and fluorine incorporated in have great application potency.

\section{References}

1 J. M. Desimone, Z. Guan and C. S. Elsbernd, Science, 1992, 257, 945-947.

2 J. W. Martin, M. M. Smithwick and B. M. Braune, Environ. Sci. Technol., 2004, 38, 373-380.

3 T. R. Dargaville, G. A. George and D. J. T. Hill, Prog. Polym. Sci., 2003, 28, 1355-1376.

4 R. Souzy and B. Ameduri, Prog. Polym. Sci., 2005, 30, 644-687. 5 J. Ding and M. Day, Macromolecules, 2006, 39, 6054-6062.

6 K. Aljoumaa, Y. Qi and J. Ding, Macromolecules, 2009, 42, 9275-9288.

7 J. Ding, X. Du and M. Day, Macromolecules, 2007, 40, 31453153.

8 J. Jiang, C. L. Callender and J. P. Noad, Opt. Eng., 2007, 46, 074601.

9 Y. Qi, J. Jiang and C. L. Callender, Appl. Opt., 2006, 45, 74807487.

10 A. Jutand and A. Mosleh, Organometallics, 1995, 14, 18101817.

11 J. Ding, Y. Qi and M. Day, Macromol. Chem. Phys., 2005, 206, 2396-2407.
12 W. Zhang, J. Xu and X. Li, J. Polym. Sci., Part A: Polym. Chem., 2014, 52, 780-788.

13 W. Zhang and A. H. E. Müller, Prog. Polym. Sci., 2013, 38, 1121-1162.

$14 \mathrm{H}$. Y. Xu, S. W. Kuo, J. S. Lee and F. C. Chang, Macromolecules, 2002, 35, 8788-8793.

15 H. Y. Xu, B. H. Yang, J. F. Wang, S. Y. Guang and C. Li, Macromolecules, 2005, 38, 10455-10460.

16 Q. He, L. Song, Y. Hu and S. J. Zhou, Mater. Sci., 2009, 44, 1308-1316.

17 W. C. Zhang, X. M. Li and R. J. Yang, J. Appl. Polym. Sci., 2012, 124, 1848-1857.

18 B. H. Augustine, W. C. Hughes, K. J. Zimmermann, A. J. Figueiredo, X. W. Guo, C. C. Chusuei and J. S. Maidment, Langmuir, 2007, 23, 4346-4350.

19 Y. J. Lee, J. M. Huang and S. W. Kuo, Polymer, 2005, 46, 10056-10065.

20 S. S. Chen, X. Li, Y. Li and J. Q. Sun, ACS Nano, 2015, 9, 40704076.

21 J. C. Huang, C. B. He and Y. Xiao, Polymer, 2003, 44, 44914499.

22 Y. Ni, S. X. Zheng and K. M. Nie, Polymer, 2004, 45, 55575568.

23 W. A. Zhang and H. E. Axel Mueller, Prog. Polym. Sci., 2013, 38, 1121-1162.

24 Y. D. Zhang, S. H. Lee and M. Yoonessi, Polymer, 2006, 47, 2984-2996.

25 S. Srinivasan, S. S. Chhatre and J. M. Mabry, Polymer, 2011, 52, 3209-3218.

26 H. Maciejewski, J. Karasiewicz and M. Dutkiewicz, Silicon, 2015, 7, 201-209.

27 R. Y. Kannan, H. J. Salacinski and M. Odlyha, Biomaterials, 2006, 27, 1971-1979.

$28 \mathrm{~J} . \mathrm{Wu}, \mathrm{Q}$. Ge and P. T. Mather, Macromolecules, 2010, 43, 7637-7649.

29 G. Li, L. Wang and H. Ni, J. Inorg. Organomet. Polym., 2001, 11, 123-154.

30 D. B. Cordes, P. D. Lickiss and F. Rataboul, Chem. Rev., 2010, 110, 2081-2173.

31 F. Laoutid, L. Bonnaud and M. Alexandre, Mater. Sci. Eng., R, 2009, 63, 100-125.

32 S. H. Phillips, T. S. Haddad and S. J. Tomczak, Curr. Opin. Solid State Mater. Sci., 2004, 8, 21-29.

33 S. W. Kuo and F. C. Chang, Prog. Polym. Sci., 2011, 36, 16491696.

34 H. Xu, S. W. Kuo and J. S. Lee, Macromolecules, 2002, 35, 8788-8793.

35 J. Wu and P. T. Mather, Polym. Rev., 2009, 49, 25-63.

36 Y. Ni, S. Zheng and K. Nie, Polymer, 2004, 45, 5557-5568.

37 B. X. Fu, B. S. Hsiao and S. Pagola, Polymer, 2001, 42, 599611.

38 C. M. Leu, Y. T. Chang and K. H. Wei, Macromolecules, 2003, 36, 9122-9127.

39 E. T. Kopesky, T. S. Haddad and R. E. Cohen, Macromolecules, 2004, 37, 8992-9004.

40 L. Matejka, A. Strachota and J. Pleštil, Macromolecules, 2004, 37, 9449-9456. 
41 Y. Ni, S. Zheng and K. Nie, Polymer, 2004, 45, 5557-5568.

42 L. Zheng, S. Hong and G. Cardoen, Macromolecules, 2004, 37, 8606-8611.

43 Y. S. Ye, W. Y. Chen and Y. Z. Wang, J. Polym. Sci., Part A: Polym. Chem., 2006, 44, 5391-5402.

44 Y. Z. Wang, W. Y. Chen and C. C. Yang, J. Polym. Sci., Part B: Polym. Phys., 2007, 45, 502-510.
45 A. G. Kannan, N. R. Choudhury and N. Dutta, ACS Appl. Mater. Interfaces, 2009, 1, 336-347.

46 N. Kitamura, T. Hiraoka and K. Tanaka, Bioorg. Med. Chem., 2012, 20, 4668-4674.

47 X. Qiang, X. Ma and Z. Li, Colloid Polym. Sci., 2014, 292, 1531-1544. 